\title{
Benchmarking network for clinical and humanistic outcomes in diabetes (BENCH-D) study: protocol, tools, and population
}

\author{
Antonio Nicolucci ${ }^{1 *}$, Maria C Rossi ${ }^{1}$, Fabio Pellegrini ${ }^{1}$, Giuseppe Lucisano ${ }^{1}$, Basilio Pintaudi ${ }^{1}$, Sandro Gentile ${ }^{2}$, \\ Giampiero Marra ${ }^{3}$, Soren E Skovlund ${ }^{4}$, Giacomo Vespasiani ${ }^{5}$, on behalf of the BENCH-D Study Group
}

\begin{abstract}
Background: In the context of the DAWN-2 initiatives, the BENCH-D Study aims to test a model of regional benchmarking to improve not only the quality of diabetes care, but also patient-centred outcomes.

Methods/Design: As part of the AMD-Annals quality improvement program, 32 diabetes clinics in 4 Italian regions extracted clinical data from electronic databases for measuring process and outcome quality indicators. A random sample of patients with type 2 diabetes filled in a questionnaire including validated instruments to assess patientcentred indicators: SF-12 Health Survey, WHO-5 Well-Being Index, Diabetes Empowerment Scale, Problem Areas in Diabetes, Health Care Climate Questionnaire, Patients Assessment of Chronic Illness Care, Barriers to Medications, Patient Support, Diabetes Self-care Activities, and Global Satisfaction for Diabetes Treatment. Data were discussed with participants in regional meetings. Main problems, obstacles and solutions were identified through a standardized process, and a regional mandate was produced to drive the priority actions. Overall, clinical indicators on 78,854 patients have been measured; additionally, 2,390 patients filled-in the questionnaire. The regional mandates were officially launched in March 2012. Clinical and patient-centred indicators will be evaluated again after 18 months. A final assessment of clinical indicators will take place after 30 months.

Discussion: In the context of the BENCH-D study, a set of instruments has been validated to measure patient wellbeing and satisfaction with the care. In the four regional meetings, different priorities were identified, reflecting different organizational resources of the different areas. In all the regions, a major challenge was represented by the need of skills and instruments to address psychosocial issues of people with diabetes. The BENCH-D study allows a field testing of benchmarking activities focused on clinical and patient-centred indicators.
\end{abstract}

Keywords: Type 2 diabetes; Quality of care; Benchmarking; Patient-centered outcomes

\section{Introduction}

The prevention of diabetes and control of its micro- and macrovascular complications has become one of the main public health challenges for the $21^{\text {st }}$ century, with the aim of attaining a significant reduction in the huge premature morbidity and mortality it causes, with a parallel reduction in health care costs (Shaw et al. 2010). To this purpose, in addition to the implementation of strategies for diabetes prevention through lifestyle modification, a

\footnotetext{
* Correspondence: nicolucci@negrisud.it

'Department of Clinical Pharmacology and Epidemiology, Mario Negri Sud

Foundation, Via Nazionale, 66030S Maria Imbaro, CH, Italy

Full list of author information is available at the end of the article
}

more aggressive control of the most important risk factors is urgently needed (American Diabetes Association 2009). In fact, despite strong evidence that pharmacological interventions play an important role in preventing complications in individuals with diabetes, the mere dissemination of evidence-based guidelines often fails to deeply influence clinical practice.

The considerable pressure on health care systems to provide high-quality care while controlling costs has led several public and private health care organizations to promote initiatives to measure and improve the quality of care for patients with diabetes (Peters et al. 1996; TRIAD Study Group 2002; Ilag et al. 2003; Saaddine et al. 
2002, 2006). Quality measures identified include process and intermediate outcome indicators, selected under the assumption that they are linked to downstream health outcomes. These measures have been widely utilized to monitor quality of care and promote continuous quality improvement initiatives (Saaddine et al. 2002, 2006).

In Italy, the Associazione Medici Diabetologi (AMD) has implemented a continuous improvement effort involving over 300 diabetes clinics throughout the Country (Rossi et al. 2008). To this purpose, AMD identified a set of quality indicators, including process and intermediate outcome measures. All indicators are compared with reference values, or "gold standard", established by identifying the best performers. By fixing as reference the results obtained by the best performers, specialists can easily realize the real margin of improvement made possible by simply increasing the level of attention to disease monitoring and treatment. The AMD Annals initiative allows a thorough description of the quality of care delivered every year by specialist structures to over 500.000 patients (Arcangeli et al. 2013). In additional to cumulative analyses, AMD Annals also provide sub-analyses at the regional level, to facilitate the local use of the data for quality improvement initiatives. The initiative has already proven to be effective in improving several quality of care indicators (Nicolucci et al. 2010).

Nevertheless, more structured benchmarking activities, involving discussion with clinicians, detection of obstacles at the local level, and identification of possible solutions are likely to produce further improvements in diabetes care. To this respect, a preliminary experience carried out in Sicily by a network of diabetes clinics documented a tangible improvement in the quality of diabetes care over 5 years (Club Diabete Sicili@ 2008).

In recent years, there has been an increasing recognition of patient-centered care as the best model to ensure a care respectful of, and responsive to patient preferences, needs, and values (Glasgow et al. 2008). The focus on patients' perspective has thus become particularly relevant. Despite the consensus that patient-centered care is an essential component of good diabetes care, most diabetes performance measures are solely based on clinical measures, and do not include psychosocial items. The need to include psychosocial aspects in the quality model of diabetes care has been clearly emphasized by the international Diabetes Attitudes, Wishes, and Needs (DAWN) Program. The DAWN Study has clearly shown that people with diabetes across 13 countries have major psychosocial issues that are not adequately addressed in the existing health care systems (Conference Report 2004; International Diabetes Federation 2004; Peyrot et al. 2005a; Skovlund and Peyrot 2005; Wroe 2006).
Given these premises, the BENCH-D Study (Benchmarking Network for Clinical and Humanistic Outcomes in Diabetes) was designed to test a model of regional benchmarking activity aimed at improving not only the quality of diabetes care, but also patient-centered outcomes. The BENCH-D study is integral part of the DAWN-2 initiatives (Peyrot et al. 2013) in Italy.

\section{Methods}

\section{Objectives}

Aims of the BENCH-D study are:

1. To tests the feasibility of a regional model for quality improvement, based on a deep analysis of regional data coupled with a structured process for the identification of priority actions;

2. To identify a core set of patient centered indicators to be adopted in conjunction with clinical indicators;

3. To evaluate the impact of the benchmarking initiative in improving both clinical and patientcentered quality indicators.

\section{Setting}

The study involves 32 diabetes clinics in four different Italian regions (Piedmont, Marche, Lazio, and Sicily). Regions have been selected to reflect different levels of performance in terms of process and intermediate outcome measures, based on the information collected in the previous analyses of AMD Annals.

\section{Clinical data collection}

Following the methodology applied in the AMD Annals initiative (Rossi et al. 2008; Arcangeli et al. 2013; Nicolucci et al. 2010), data are extracted from electronic databases of diabetes clinics using a specific software. Information on all patients seen in the clinic in the previous 12 months is collected, including age, gender, body mass index (BMI), smoking, diabetes duration, diabetes treatments, glycated hemoglobin (HbA1c), blood pressure and lipid profile values, microalbuminuria, serum creatinine, antihypertensive and lipid-lowering treatments, diabetes complications and other chronic conditions. A set of standard quality of care indicators is adopted, including process, intermediate and final outcomes, indicators of treatment intensity/appropriateness, and a global quality score.

Process measures are expressed as percentages of patients monitored at least once during the previous 12 months for the following parameters: HbA1c, blood pressure (BP), lipid profile, renal function, foot examination and eye examination.

Intermediate outcome measures include the proportion of patients with satisfactory values as well as the percentage of those with unacceptably high values. Satisfactory 
outcomes include HbA1c levels $\leq 7.0 \%$ (53 mmol/mol), BP values $\leq 130 / 80 \mathrm{mmHg}$, LDL cholesterol (LDL-C) levels $<100 \mathrm{mg} / \mathrm{dl}$, and body mass index (BMI) $<27 \mathrm{Kg} / \mathrm{m}^{2}$. Unsatisfactory outcomes include HbA1c levels >8.0\% (64 $\mathrm{mmol} / \mathrm{mol}$ ), blood pressure values $\geq 140 / 90 \mathrm{mmHg}$, LDL levels $\geq 130 \mathrm{mg} / \mathrm{dl}$, BMI $\geq 30 \mathrm{Kg} / \mathrm{m}^{2}$, presence of $\mathrm{mi}$ cro/macroalbuminuria, and GFR $\leq 60 \mathrm{ml} / \mathrm{min}$.

Indicators of treatment intensity/appropriateness take into consideration the use of pharmacological treatments in relation to the achievement of the targets. This set includes: no insulin treatment in spite of HbA1c $>9.0 \%$ (75 mmol/mol); HbA1c $>9.0 \%(75 \mathrm{mmol} / \mathrm{mol})$ in spite of insulin treatment; no lipid-lowering agents in spite of LDL-c $\geq 130 \mathrm{mg} / \mathrm{dl}$; LDL-c $\geq 130 \mathrm{mg} / \mathrm{dl}$ in spite of lipidlowering treatment; no antihypertensive treatments in spite of $\mathrm{BP} \geq 140 / 90 \mathrm{mmHg}$; $\mathrm{BP} \geq 140 / 90 \mathrm{mmHg}$ in spite of antihypertensive treatment; no ACE-inhibitors (ACE-I) and/or Angiotensin Receptor Blockers (ARBs) in spite of micro/macroalbuminuria.

A quality of care summary score ( $Q$ score) is also calculated. The $\mathrm{Q}$ score has been developed and validated in two previous studies (De Berardis et al. 2008; Rossi et al. 2011); it is based on a combination of process and intermediate outcome indicators relative to $\mathrm{HbA} 1 \mathrm{c}$, blood pressure, LDL-cholesterol and microalbuminuria. The score ranges between 0 and 40; the higher the score, the better the quality of care. The risk to develop a new cardiovascular event within 3 years was shown to be $80 \%$ higher in patients with a score $<15$ and $20 \%$ higher in those with a score between 15 and 25, as compared to those with a score $>25$ (De Berardis et al. 2008; Rossi et al. 2011).

\section{Quality of life and patient satisfaction evaluation}

Information on quality of life and patient satisfaction is collected using ad hoc questionnaires. The questionnaire includes ten instruments, partially derived from the DAWN-2 study (Peyrot et al. 2013).

Standardized instruments were incorporated into the questionnaires in original or shortened forms: SF-12 health survey, WHO Well-Being Index (WHO-5), Diabetes Empowerment Scale-Short Form (DES-SF), Problem Areas in Diabetes Scale 5 (PAID-5), Patient Assessment of Chronic Illness Care-Short Form (PACIC-SF), Health Care Climate Short Form (HCC-SF), Global Satisfaction with Diabetes Treatment (GSDT), Summary of Diabetes SelfCare Activities measure (SDSCA-6); Barriers to Medications (BM), Perceived Social Support (PSS).

All the questionnaires, with the exception of the already previously validated WHO-5 Well-Being Index (Bech et al. 1996; Hajos et al. 2013), have undergone a rigorous process of translation into the Italian language and psychometric validation specifically for the BENCH-D study. All the scale scores, with the exception of SDSCA-
6 , range between 0 and 100, with higher values indicating a higher level of the dimension measured.

- SF-12 Health Survey (SF-12): it is a widely used generic health status measure (Gandek et al. 1998). It includes 12 items which can be aggregated into two summary measures: the Physical (PCS) and Mental (MCS) Component Summary scores. Both scores are normalized to a general population mean of 50 and a standard deviation of 10 .

- WHO-5 Well-Being Index (WHO-5): It assesses the psychological well-being, a core component of overall quality of life (Bech et al. 1996; Hajos et al. 2013). The use of WHO-5 is recommended in global and some national treatment guidelines for diabetes after its worldwide use in the DAWN initiative (Conference Report 2004; International Diabetes Federation 2004; Peyrot et al. 2005b, 2013; Skovlund and Peyrot 2005; Wroe 2006). It is also a valid and reliable risk assessment measure for mild, moderate and severe depression and performs well in comparison to negative worded instruments such as the Brief Patient Health Questionnaire PHQ-9 or CES-D (Henkel et al. 2003; de Wit et al. 2007). It includes 5 items with responses on a six-point Likert scale. A score $<50$ indicates poor psychological well-being, while a score $\leq 28$ indicates likely depression.

\section{- Diabetes Empowerment Scale - Short Form} (DES-SF): DES-SF provides a very brief but well validated instrument to assess the patient's confidence in taking an active role in own management of the condition (Anderson et al. 2000, 2003). An effective diabetes management requires an empowered diabetes patient, who is able to take personal charge of parts of the care plan, yet the extent to which educational and pedagogic efforts of the healthcare team are effective in empowering the patient is rarely measured. The instrument includes 8 items with responses on a fivepoint Likert scale.

- Problem Areas in Diabetes - Short form (PAID-5): PAID evaluates the emotional diabetes distress, i.e. patients specific worries and negative emotions related to their diabetes (McGuire et al. 2010; Polonsky et al. 1995; Welch et al. 2003). It also complements the general well-being assessment with vital information about the patient's acceptance of and coping with diabetes-specific issues. The instrument has been applied in more than a hundred studies and in the DAWN MIND (Monitoring Individual Needs in People with Diabetes) program across 10 countries (McGuire et al. 2010). The PAID-5 short-form has been validated in the multi-national DAWN MIND study and there is solid evidence that scores are clinically relevant. It includes 5 items with responses 
on a five-point Likert scale. A score $\geq 40$ indicates high diabetes-related distress.

- Patients Assessment of Chronic Illness Care - Short form (PACIC-SF): In accordance with the evidencebased principles of patient-centered healthcare and the results of the DAWN initiative, the PACIC scale enables a concrete assessment of patient perceived access to support from the health care team according to a chronic care health delivery model (Glasgow et al. 2005; Gugiu et al. 2009). In this study we used the short-form version of the questionnaire, including 11 items with responses on a five-point Likert scale.

- Health Care Climate Questionnaire - Short form (HCC-SF): it evaluates the extent to which clinicians tend to favor the autonomy of the patient or, instead, tend to assume a paternalistic attitude towards the patient (Williams et al. 2004). This instrument has been used in many studies on different diseases, including diabetes, and has proven to be able to predict an improvement in metabolic control (Schafer et al. 1986). The study uses a short version of the questionnaire, consisting of 6 questions, with responses on 7-point Likert scale.

- Global Satisfaction with Diabetes Treatment (GSDT): It assesses the perceived impact of medication on daily life and psychological well being, in addition to overall satisfaction for the pharmacological treatment (Brod et al. 2006). It represents a very important element in determining the acceptance by the patient and adherence to therapy. The questionnaire was developed as part of the DAWN Study, and consists of 7 items with responses on 5-point Likert scales.

- Summary of Diabetes Self-care Activities (SDSCA-6): it assesses health behaviours, notoriously difficult to evaluate reliably. The instrument has been shown to add relevant and useful information in the context of diabetes studies, even though data must be interpreted with caution as they are self-reported (Toobert et al. 2000). The version of the SDSCA- 6 includes 6 selected items with responses on 8-point Likert scales, indicating the number of days (from 0 to 7 ) in a week the patient adheres with the recommended behaviour. Each item is treated individually.

- Barriers to Medications (BM): Compliance to medication is considered a key reason for suboptimal outcomes (Brod et al. 2006; Snoek et al. 2007; Anderson et al. 2004). BM is a simple questionnaire focused on assessing what concrete barriers patients face in daily life to taking their medication as scheduled. It has been developed in the DAWN study (Conference Report 2004; International Diabetes Federation 2004; Peyrot et al. 2005b, 2013; Skovlund and Peyrot 2005; Wroe 2006) and includes 10 items with responses on 6-point Likert scales.

- Perceived social support (PSS): as demonstrated by the international DAWN study (Conference Report 2004; International Diabetes Federation 2004; Peyrot et al. 2005b, 2013; Skovlund and Peyrot 2005; Wroe 2006), patient perception of access to support from multiple sources plays an important role. People with diabetes rely on support from the community, from family, peers and other sources on a daily basis, and understanding this level of support in addition to that provided by the healthcare system is essential, yet requires new questionnaires. The DAWN study included a very short questionnaire to assess satisfaction with support from various sources, which proved useful in determining the relative importance of these factors in patient's selfmanagement (Peyrot and International DAWN Youth Survey Group 2009). An optimized version of the questionnaire has been included in this study, including 5 items with responses on 5-point Likert scale.

Table 1 Study design

\begin{tabular}{|c|c|c|c|}
\hline Time & Period & Regional meeting & Activity \\
\hline $\mathrm{T}-1$ & October - November 2010 & First meeting & Presentation of the protocol \\
\hline T0 & November 2010 - July 2011 & & $\begin{array}{l}\text { Administration of the first questionnaire to a random sample of patients. } \\
\text { First clinical data extraction. }\end{array}$ \\
\hline $\mathrm{T} 2$ & September - October 2011 & Second + third meeting & $\begin{array}{l}\text { Discussion of clinical and patient-centered indicators and definition of } \\
\text { the regional mandate. }\end{array}$ \\
\hline T3 & March 2012 & & Activation of regional mandate in the centers. \\
\hline $\mathrm{T} 4$ & March - July 2013 & & $\begin{array}{l}\text { Patient recall and administration of the second questionnaire. } \\
\text { Second clinical data extraction. }\end{array}$ \\
\hline T5 & September - November 2013 & Fourth meeting & $\begin{array}{l}\text { Intermediate evaluation of the impact of benchmarking on clinical indicators. } \\
\text { Final evaluation of the impact of benchmarking on patient-centered indicators. }\end{array}$ \\
\hline T6 & July 2014 & & Third clinical data extraction. \\
\hline $\mathrm{T} 7$ & September - November 2014 & Fifth meeting & Final evaluation of the impact of benchmarking on clinical indicators. \\
\hline
\end{tabular}


Information on socio-demographic characteristics (age, gender, nationality, level of school education, working status, living status) are also collected through the questionnaire.

Questionnaires are anonymous, filled in by the patients on the occasion of a routine visit and sent to the coordinating center using sealed envelopes. The link between clinical and patient reported data is ensured by a univocal numerical code.

\section{Patient recruitment}

All patients seen in the participating centers during the previous 12 months are included in the evaluation of clinical indicators. Patient centered outcomes are evaluated in a sub-sample of patients, selected using random sampling lists, stratified by diabetes treatment (oral agents, insulin, insulin and oral agents). An additional sample of patients with newly diagnosed diabetes (diagnosis made in the last 12 months) has been also identified. Within each treatment group, the sample has been further stratified by gender.

\section{Regional meetings}

In each region, 5 meetings are scheduled, involving all the health care professionals participating in the initiative (diabetologists, nurses, dietitians).

In the first meeting, the aims and the operational aspects of the study were illustrated and discussed with participants.

The second meeting was focused on the discussion of the results relative to clinical indicators produced by the AMD Annals at the national and regional level. The "best performers" approach was used to compare the overall results obtained at the regional level with those obtained in those centers reaching the highest rates of performance for process and outcome measures. The session was organized according to a standardized structure. After the illustration of the results, each participant was asked to identify the three main problems emerging from the data. All the problems identified were then assigned by the participants a score from 0 to 10 for their relevance and a score from 0 to 10 for the concrete possibility to act on the problem. Problems were then ranked, and the first three were selected. Following the same procedure, three major obstacles causing the problems were identified and possible solutions proposed. The process led to the definition of a regional mandate, to be implemented in the following 12 months. The mandate did not require a radical change in the usual clinical practice, but rather an optimization of the work already done and a more appropriate use of the available resources.

The third meeting was focused on patient centered outcomes. Following the same methodology of the previous meeting, results of the quality of life and satisfaction
Table 2 Socio-demographic and clinical characteristics of patients recruited in the BENCH-D study

\begin{tabular}{llc}
\hline Variable & & $\begin{array}{c}\text { Mean } \pm \text { std } \\
\text { or } \%\end{array}$ \\
\hline $\mathbf{N}$ & 2,390 \\
$\begin{array}{l}\text { Socio-demographic } \\
\text { characteristics } \\
\text { \% Males }\end{array}$ & \\
Mean age (years) & & $59.7 \%$ \\
School education (\%) & Primary school & $65.0 \pm 10.2$ \\
& Middle school & 39.2 \\
& High school & 28.8 \\
& University & 25.4 \\
Working status (\%) & Employed & 6.6 \\
& Housewife & 23.5 \\
& Retired & 14.4 \\
& Unemployed/student & 59.7 \\
& Not married & 6.4 \\
Marital status (\%) & Married & 77.9 \\
& Separated/divorced & 4.4 \\
& Widower & 10.9 \\
Smokers (\%) & Alone & 11.9 \\
& Spouse/sons & 82.8 \\
Living status (\%) & Other & 5.2 \\
& & 16.5 \\
& & \\
& &
\end{tabular}

\section{Clinical characteristics}

Diabetes duration (yrs)

HbA1c (\%)

$\mathrm{HbA1c}(\mathrm{mmol} / \mathrm{mol})$

BMI $\left(\mathrm{Kg} / \mathrm{m}^{2}\right)$

Total cholesterol $(\mathrm{mg} / \mathrm{dl})$

HDL cholesterol (mg/dl)

LDL cholesterol (mg/dl)

Triglycerides (mg/dl)

Systolic blood pressure

Diastolic blood pressure

$14.0 \pm 15.3$

$7.7 \pm 1.5$

$61 \pm 16.4$

$30.2 \pm 6.0$

$177.7 \pm 39.9$

$49.5 \pm 14.6$

$100.9 \pm 32.7$

$142.4 \pm 112.4$

$135.3 \pm 16.2$

Diabetes treatment (\%)

$78.3 \pm 9.1$

$\begin{array}{ll}\text { Oral agents } & 49.5 \\ \text { Oral agents + insulin } & 25.8 \\ \text { Insulin } & 24.7\end{array}$

Lipid-lowering agents (\%)

47.1

Antihypertensive treatment (\%) $\quad 67.7$

Diabetes complications $\quad 0 \quad 66.6$

25.0

8.4 
Table 3 Quality of life and patient satisfaction questionnaires used and validated in the BENCH-D study

\begin{tabular}{|c|c|c|c|c|c|c|}
\hline Questionnaire & Abbreviation & Domain & $\begin{array}{l}\text { No. of } \\
\text { items }\end{array}$ & Scoring & $\begin{array}{l}\text { Cronbach's } \\
\text { alpha }\end{array}$ & $\begin{array}{l}\text { Item-scale } \\
\text { correlation } \\
\text { (Min-Max) }\end{array}$ \\
\hline SF-12 Health Survey physical component & SF-12 PCS & Physical functioning & 6 & $0-100$ & - & - \\
\hline WHO-5 Well-Being Index & WHO-5 & Psychological well-being & 5 & $0-100$ & - & - \\
\hline Diabetes Empowerment Scale-Short Form & DES-SF & Diabetes Psychosocial Self-Efficacy & 8 & $0-100$ & 0.93 & $0.916-0.933$ \\
\hline Problem Areas in Diabetes 5 & PAID-5 & Diabetes distress & 5 & $100-0$ & 0.93 & $0.918-0.923$ \\
\hline Health Care Climate Questionnaire-Short Form & HCC-SF & Patient centered communication & 6 & $0-100$ & 0.93 & $0.909-0.927$ \\
\hline $\begin{array}{l}\text { Patients Assessment of Chronic Illness } \\
\text { Care-Short Form }\end{array}$ & PACIC-SF & $\begin{array}{l}\text { Quality of chronic illness care } \\
\text { and patient support }\end{array}$ & 11 & $0-100$ & 0.85 & $0.833-0.849$ \\
\hline Global Satisfaction for Diabetes Treatment & GSDT & Satisfaction with treatment regimen & 7 & $0-100$ & 0.80 & $0.748-0.787$ \\
\hline Diabetes Self-care Activities & SDSCA-6 & Self-care activities & 6 & $0-7$ & - & - \\
\hline Barriers to Medications & BM & Barriers to medication & 10 & $0-100$ & 0.77 & $0.736-0.753$ \\
\hline Perceived social support & PSS & Patient perceived support & 5 & $0-100$ & 0.81 & $0.748-0.830$ \\
\hline
\end{tabular}

survey were discussed, problems/barriers were identified, and possible solutions/actions proposed.

Eighteen months after the third meeting, clinical data will be extracted again, allowing a first evaluation of the impact of the initiative on clinical indicators. The impact of benchmarking activities on patient centered outcomes will be evaluated following a second survey conducted with the same patients participating in the first one. The results will be discussed on the occasion of the fourth meeting. Improvements registered and problematic areas where no improvements in performance will be documented will represent the core for discussion. Elements that have facilitated or represented an obstacle to improvement will be analyzed in detail, and actions to improve quality of care will be identified.

A final data collection on clinical indicators will be performed 12 months after the second clinical data extraction, and results will be discussed in the fifth meeting, which will represent the occasion for the assessment of the overall outcomes of the initiative. The results of this final assessment will be useful to identify the strengths and limitations of the approach adopted, and will help in better refining the overall approach before its extension to other regions.

The study design is reported in Table 1.

\section{Statistical analysis}

Except for the SF-12 and the WHO-5, largely utilized in the Italian population, all the other quality of life scales have been translated, cross-culturally adapted and validated in Italian specifically for the BENCH-D study. The questionnaire was validated using a multitrait multi-item method (Ware et al. 1997). This method is used to determine whether each item in a scale is substantially related $(r \geq 0.40)$ to the total score computed from the other items in that scale (item convergent validity criterion). Internal-consistency reliability was estimated by the Cronbach's alpha coefficient, with a minimum value of 0.70 considered as acceptable. Furthermore, the percentages of respondents achieving either the highest score (ceiling) and lowest score (floor) were calculated.

Table 4 Examples of actions identified in the regional mandate

\begin{tabular}{|c|c|c|}
\hline Problem area & Action & Quality indicator to measure impact of benchmarking \\
\hline $\begin{array}{l}\text { Many patients with microalbuminuria } \\
\text { are not treated with ACE-inhibitors } \\
\text { and/or ARBs }\end{array}$ & $\begin{array}{l}\text { Use of an ad hoc query on the electronic } \\
\text { clinical record to identify these patients }\end{array}$ & $\begin{array}{l}\text { Reduction in the percentage of patients with microalbuminuria } \\
\text { not treated with ACE-inhibitors and/or ARBs }\end{array}$ \\
\hline $\begin{array}{l}\text { Many patients with LDL-cholesterol } \\
\geq 130 \mathrm{mg} / \mathrm{dl} \text { are not treated with } \\
\text { lipid-lowering agents }\end{array}$ & $\begin{array}{l}\text { Use of an ad hoc query on the electronic } \\
\text { clinical record to identify these patients }\end{array}$ & $\begin{array}{l}\text { Reduction in the percentage of patients with LDL-C } \geq 130 \mathrm{mg} / \mathrm{dl} \\
\text { not treated with lipid-lowering agents }\end{array}$ \\
\hline $\begin{array}{l}\text { Poor proactive involvement of } \\
\text { patients in the process of care }\end{array}$ & $\begin{array}{l}\text { Identification of a model of "therapeutic } \\
\text { contract", with discussion and agreement } \\
\text { on therapeutic goals and appointments } \\
\text { for regular monitoring of diabetes } \\
\text { complications }\end{array}$ & $\begin{array}{l}\text { Increase in the percentage of patients reaching } \mathrm{HbA} 1 \mathrm{c} \text {, blood } \\
\text { pressure and LDL-cholesterol targets. Increase in percentage } \\
\text { patients monitored for nephropathy, retinopathy and diabetic } \\
\text { foot }\end{array}$ \\
\hline $\begin{array}{l}\text { Poor attention to patient with low } \\
\text { levels of psychological well-being }\end{array}$ & $\begin{array}{l}\text { Use of WHO-5 to identify patients with } \\
\text { score }<28 \text {; referral for specific counseling, } \\
\text { identification of barriers and solutions }\end{array}$ & $\begin{array}{l}\text { Increase in mean values of WHO-5 and DES-SF scores and } \\
\text { decrease in mean values of PAID-5 }\end{array}$ \\
\hline
\end{tabular}


Patient characteristics and clinical indicators are described as mean and standard deviation or frequencies.

Scale scores are summarized as mean and standard deviation. All the data have been centrally analyzed anonymously.

\section{Ethics considerations}

The study protocol was approved by local ethics committees of participating centers. A written informed consent was obtained by all patients before the administration of the questionnaires.

The protocol was approved by the institutional review board of the Mario Negri Sud Foundation and by the scientific committee of the Associazione Medici Diabetologi.

\section{Results}

\section{Recruitment}

Overall, 32 centers extracted by the electronic clinical record system information on 78,854 patients with type 2 diabetes for benchmarking activities based on clinical indicators, while 26 centers enrolled 2,390 patients for the validation and evaluation of patient centered outcomes. Socio-demographic and clinical characteristics of the patients who filled in the questionnaire are summarized in Table 2.

\section{Validation of the questionnaires}

The validation process was performed using all the questionnaires filled in by 2,390 patients enrolled. All the questionnaires showed excellent psychometric characteristics; for all scales, the Cronbach's alpha coefficient largely exceeded the minimum accepted value of 0.70 (Table 3). On the same line, item-scale correlation was extremely satisfactory for all the scales. Percentages at ceiling and floor were equal to $0 \%$ for DES-SF, HCC-SF, PACIC-SF, GSDT, PSS, and BM and in an acceptable range for PAID-5 (10.2\% at floor and 0\% at ceiling).

\section{Regional meetings}

Meetings for the structured discussion of clinical and humanistic indicators have been held between September and October 2011. The approach adopted led to the identification of different priorities for intervention in the four regions, reflecting different organizational characteristics and specific needs.

The operational protocol has been officially launched in March 2012. The biggest challenge identified in all regions was to test innovative ways of communication with the patient, and to deal with his/her psychosocial needs. Table 4 shows as an example the problems and solutions proposed in one of the regions.

\section{Discussion}

The BENCH-D study allows the field testing of benchmarking activities based on a structured discussion of quality indicators, selection of priorities, and identification pertinent actions. Furthermore, the study includes for the first time in a benchmarking initiative a set of validated patient centered indicators and will document whether it is possible to improve not only clinical indicators, but also patient well-being and satisfaction with the care received. If successful, the initiative could be extended to other Italian regions, as well as to other health care systems. As a whole, this project can make an important contribution in promoting patient-centered care and improving the quality of diabetes care.

\section{Abbreviations \\ AMD: Associazione Medici Diabetologi; DAWN: Diabetes Attitudes, Wishes, and Needs (DAWN) Program; BENCH-D: Benchmarking Network for Clinical and Humanistic Outcomes in Diabetes Study; BMl: Body mass index; HbA1c: Glycated hemoglobin; BP: Blood pressure; LDL-c: LDL cholesterol; ACE-I: ACE-inhibitors; ARBs: Angiotensin Receptor Blockers; Q score: Quality of care summary score; SF-12 PCS: SF-12 Health Survey physical component WHO-5: WHO-5 well-being index; DES-SF: Diabetes Empowerment Scale- Short Form; PAID-5: Problem Areas in Diabetes 5; HCC-SF: Health Care Climate Questionnaire-Short Form; PACIC-SF: Patients Assessment of Chronic IIIness Care-Short Form; GSDT: Global Satisfaction for Diabetes Treatment; SDSCA-6: Diabetes Self-care Activities; BM: Barriers to Medications; \\ PSS: Perceived social support.}

\section{Competing interests}

AN is a member of the advisory board of Novo Nordisk, Novartis, Merk Sharp \& Dohme. He has received speaker fees from Novo Nordisk, Novartis, Merk Sharp \& Dohme; GM is an employee of Novo Nordisk, Rome, Italy; SES is an employee of Novo Nordisk A/S, Copenhagen, Denmark. All other authors declare that they have no conflict of interest.

\section{Authors' contributions}

AN conceived the study, AN and MCR designed the study protocol, and SG and GV contributed to the study design. GV and BP researched data. MCR and BP coordinate the study. GM supported the study. AN, MCR, and BP wrote the manuscript, FP and GL performed the statistical analyses. GM, SS SG and GV revised critically and approved the manuscript. All authors read and approved the final manuscript

\section{Acknowledgments}

We acknowledge all participating centers and Novo Nordisk SpA, Italy for the non-conditioning support to the study.

\section{The BENCH-D Study Group}

Scientific Committee: A Nicolucci, Mario Negri Sud Foundation, Chieti, G Vespasiani, Osp. Madonna del Soccorso, S. Benedetto del Tronto (AP) MC Rossi, Mario Negri Sud Foundation, Chieti, S Gentile, Università "Federico II", Napoli, G Marra, Novo-Nordisk SpA, Roma, Soren Eik Skovlund, Novo-Nordisk A/S, Copenaghen, Denmark.

Participating Centers (by region): LAZIO: E Forte, F Tuccinardi, A Griffo, Fondi (LT); S Leotta, L Fontana, M Altomare, L Pellegrini, Roma; F Malci, C Moscatelli, Subiaco (RM); P Tatti, M Neri, Marino (RM); G Santantonio, Civitavecchia (RM); F Chiaramonte, Roma; MARCHE: RA Rabini, S Rosati, F D'Angelo, Ancona; G Maolo, B Polenta, S Lardelli, AM Tesi, Macerata; L Cotti, G Garrapa, R Viola, M Manuela, F Lizzadro, Fano (PU); MG Cartechini, N Busciantella Ricci, G Agostinelli, Camerino (MC); G Vespasiani, I Meloncelli, M Galetta, V Marconi, L Carini, I Crema, L Clementi, San Benedetto del Tronto (AP); S Manfrini, L Olivi, Senigallia (AN); P Foglini, R Maricotti, P Pantanetti, Fermo; A Spalluto, Pesaro; M Andreani, G Martinelli, Urbino (PU); PIEMONTE: R Fornengo, A Chiambretti, L Di Vito, M Albertone, V Magliano, D Cortale, Chivasso (TO); AR Bogazzi, M Rivelli, SB Del Rosso, F Picataggi, P Bonfani, E Baccaro, Venaria Reale (TO); M Comoglio, R Manti, O Boscolo, C Laiolo, 
Moncalieri (TO); A Clerico, L Richiardi, K Sinato, Torino; GP Carlesi, S Garrone, Novi Ligure (AL); G Magro, C Paverin, D Gaviglio, Cuneo; G Saglietti, Omegna (VB); L Monge, Torino; G Grassi, Torino; SICILIA: A Di Benedetto, M Russo, B Pintaudi, G Di Vieste, Messina; A Garofalo, F Vitale, L Bernardo, Vittoria (RG); G Saitta, Messina; A Lo Presti, Marsala (TP); MA Fulantelli, Palermo; G Mattina, M Cortese, A Parrinello, Palermo; V Provenzano, L Ferrara, R Ferranti, Partinico (PA); D Gioia, M Conti, Palermo.

Coordinating Center: A Nicolucci, MC Rossi, B Pintaudi, F Pellegrini, G Lucisano, M Valentini, D D’Alonzo, C Pirozzoli, R Memmo, B Di Nardo, Laboratory of Clinical Epidemiology of Diabetes and Chronic Diseases, Mario Negri Sud Foundation, S Maria Imbaro (CH), Italy.

Data Managers and AMD Regional Coordinators: L Fontana, F Chiaramonte (Lazio); R Viola, L Cotti (Marche); R Chiodo, L Monge (Piemonte); B Pintaudi, C De Francesco (Sicilia).

\section{Author details}

${ }^{1}$ Department of Clinical Pharmacology and Epidemiology, Mario Negri Sud Foundation, Via Nazionale, 660305 Maria Imbaro, CH, Italy. '2Department of Clinical and Experimental Medicine, Second University of Naples, Naples, Italy. ${ }^{3}$ Novo Nordisk SpA, Rome, Italy. ${ }^{4}$ Skovlund SE, Novo Nordisk A/S, Bagsværd, Denmark. ${ }^{5}$ Diabetes Unit, Madonna del Soccorso Hospital, San Benedetto del Tronto, AP, Italy.

\section{Received: 30 October 2013 Accepted: 3 February 2014} Published: 12 February 2014

\section{References}

American Diabetes Association (2009) Standards of medical care in diabetes2009. Diabetes Care 32:S13-S61

Anderson RM, Funnell MM, Fitzgerald JT, Marrero DG (2000) The diabetes empowerment scale: a measure of psychosocial self-efficacy. Diabetes Care 23:739-743

Anderson RM, Fitzgerald JT, Gruppen LD, Funnell MM, Oh MS (2003) The diabetes empowerment scale-short form (DES-SF). Diabetes Care 26:1641-1642

Anderson RT, Skovlund SE, Marrero D, Levine DW, Meadows K, Brod M, Balkrishnan R (2004) Development and validation of the insulin treatment satisfaction questionnaire. Clin Ther 26:565-578

Arcangeli A, Cimino A, Di Bartolo P, Fava D, Lovagnini-Scher A, Marangoni A, Meloncelli I, Mulas MF, Nicolucci A, Nogara A, Pellegrini F, Rocca A, Rossi MC, Turco S, Vespasiani G (2013) Longitudinal analysis of quality indicators of diabetes care in Italy (2004-2011). Kino, Torino

Bech P, Gudex C, Johansen KS (1996) The WHO (ten) well-being index: validation in diabetes. Psychother Psychosom 65:183-190

Brod M, Skovlund SE, Wittrup-Jensen KU (2006) Measuring the impact of diabetes through patient report of treatment satisfaction, productivity and symptom experience. Qual Life Res 15:481-491

Club Diabete Sicili@ (2008) Five-year impact of a continuous quality improvement effort implemented by a network of diabetes outpatient clinics. Diabetes Care 31:57-62

Conference Report (2004) 2nd International DAWN Summit: a call-to-action to improve psychosocial care for people with diabetes. Practical Diabetes International 21:201-208

De Berardis G, Pellegrini F, Franciosi M, Belfiglio M, Di Nardo B, Greenfield S, Kaplan SH, Rossi MC, Sacco M, Tognoni G, Valentini M, Nicolucci A, QuED (Quality of Care and Outcomes in Type 2 Diabetes) Study Group (2008) Quality of diabetes care predicts the development of cardiovascular events: results of the QuED study. Nutr Metab Cardiovasc Dis 18:57-65

de Wit M, Pouwer F, Gemke RJ, Delemarre-van de Waal HA, Snoek FJ (2007) Validation of the WHO-5 Well-Being Index in adolescents with type 1 diabetes. Diabetes Care 30:2003-2006

Gandek B, Ware JE, Aaronson NK, Apolone G, Bjorner JB, Brazier JE, Bullinger M, Kaasa S, Leplege A, Prieto L, Sullivan M (1998) Cross-validation of item selection and scoring for the SF-12 Health Survey in nine countries: results from the IQOLA Project. International Quality of Life Assessment. J Clin Epidemiol 51:1171-1178

Glasgow RE, Wagner EH, Schaefer J, Mahoney LD, Reid RJ, Greene SM (2005) Development and validation of the patient assessment of chronic illness care (PACIC). Med Care 43:436-444

Glasgow RE, Peeples M, Skovlund SE (2008) Where is the patient in diabetes performance measures? The case for including patient-centered and self-management measures. Diabetes Care 31:1046-1050
Gugiu PC, Coryn C, Clark R, Kuehn A (2009) Development and evaluation of the short version of the Patient Assessment of Chronic Illness Care instrument. Chron Illness 5:268-276

Hajos TR, Pouwer F, Skovlund SE, Den Oudsten BL, Geelhoed-Duijvestijn PH, Tack C, Snoek FJ (2013) Psychometric and screening properties of the WHO-5 well-being index in adult outpatients with Type 1 or Type 2 diabetes mellitus. Diabet Med 30:e63-e69

Henkel V, Mergl R, Kohnen R, Maier W, Möller HJ, Hegerl U (2003) Identifying depression in primary care: a comparison of different methods in a prospective cohort study. Br Med J 326:200-201

Ilag LL, Martin CL, Tabaei BP, Isaman DJ, Burke R, Greene DA, Herman WH (2003) Improving diabetes processes of care in managed care. Diabetes Care 26:2722-2727

International Diabetes Federation (2004) Putting people at the centre of care: DAWN in action. Diabetes Voice 49:1-49

McGuire BE, Morrison TG, Hermanns N, Skovlund S, Eldrup E, Gagliardino J, Kokoszka A, Matthews D, Pibernik-Okanović M, Rodríguez-Saldaña J, de Wit M, Snoek FJ (2010) Short-form measures of diabetes-related emotional distress: the Problem Areas in Diabetes Scale (PAID)-5 and PAID-1. Diabetologia 53:66-69

Nicolucci A, Rossi MC, Arcangeli A, Cimino A, de Bigontina G, Fava D, Gentile S, Giorda C, Meloncelli I, Pellegrini F, Valentini U, Vespasiani G, AMD-Annals Study Group (2010) Four-year impact of a continuous quality improvement effort implemented by a network of diabetes outpatient clinics: the AMD-Annals initiative. Diabet Med 27:1041-1048

Peters AL, Legorreta AP, Ossorio RC, Davidson MB (1996) Quality of outpatient care provided to diabetic patients: a health maintenance organization experience. Diabetes Care 19:601-606

Peyrot M, International DAWN Youth Survey Group (2009) The DAWN Youth WebTalk Study: methods, findings, and implications. Pediatr Diabetes 13:S37-S45

Peyrot M, Rubin RR, Lauritzen T, Skovlund SE, Snoek FJ, Matthews DR, Landgraf R, Kleinebreil L, International DAWN Advisory Panel (2005a) Resistance to insulin therapy among patients and providers. Results of the cross-national Diabetes Attitudes, Wishes, and Needs (DAWN) study. Diabetes Care 28:2673-2679

Peyrot M, Rubin RR, Lauritzen T, Snoek FJ, Matthews DR, Skovlund SE (2005b) Psychosocial problems and barriers to improved diabetes management: results of the Cross-National Diabetes Attitudes, Wishes and Needs (DAWN) Study. Diabet Med 22:1379-1385

Peyrot M, Burns KK, Davies M, Forbes A, Hermanns N, Holt R, Kalra S, Nicolucci A, Pouwer F, Wens J, Willaing I, Skovlund SE (2013) Diabetes Attitudes Wishes and Needs 2 (DAWN2): a multinational, multi-stakeholder study of psychosocial issues in diabetes and person-centred diabetes care. Diabetes Res Clin Pract 99:174-184

Polonsky WH, Anderson BJ, Lohrer PA, Welch G, Jacobson AM, Aponte JE, Schwartz CE (1995) Assessment of diabetes-related distress. Diabetes Care 18:754-760

Rossi MC, Nicolucci A, Arcangeli A, Cimino A, De Bigontina G, Giorda C, Meloncelli I, Pellegrini F, Valentini U, Vespasiani G, Associazione Medici Diabetologi Annals Study Group (2008) Baseline quality-of-care data from a quality-improvement program implemented by a network of diabetes outpatient clinics. Diabetes Care 31:2166-2168

Rossi MC, Lucisano G, Comaschi M, Coscelli C, Cucinotta D, Di Blasi P, Bader G, Pellegrini F, Valentini U, Vespasiani G, Nicolucci A, AMD-QUASAR Study Group (2011) Quality of diabetes care predicts the development of cardiovascular events: results of the AMD-QUASAR study. Diabetes Care 34:347-352

Saaddine JB, Engelgau MM, Beckles GL, Gregg EW, Thompson TJ, Narayan KM (2002) A diabetes report card for the United States: quality of care in the 1990s. Ann Intern Med 136:565-574

Saaddine JB, Cadwell B, Gregg EW, Engelgau MM, Vinicor F, Imperatore G, Narayan KM (2006) Improvements in diabetes processes of care and intermediate outcomes: United States, 1988-2002. Ann Intern Med 144:465-474

Schafer LC, McCaul KD, Glasgow RE (1986) Supportive and nonsupportive family behaviors: relationships to adherence and metabolic control in persons with type I diabetes. Diabetes Care 9:179-185

Shaw JE, Sicree RA, Zimmet PZ (2010) Global estimates of the prevalence of diabetes for 2010 and 2030. Diabetes Res Clin Pract 87:4-14

Skovlund SE, Peyrot M (2005) The Diabetes Attitudes, Wishes, and Needs (DAWN) program: a new approach to improving outcomes in diabetes care. Diabetes Spectrum 18:136-142 
Snoek FJ, Skovlund SE, Pouwer F (2007) Development and validation of the insulin treatment appraisal scale (ITAS) in patients with type 2 diabetes. Health Qual Life Outcomes 5:69

Toobert DJ, Hampson SE, Glasgow RE (2000) The summary of diabetes self-care activities measure: results from 7 studies and a revised scale. Diabetes Care 23:943-950

TRIAD Study Group (2002) The Translating Research Into Action for Diabetes (TRIAD) Study: a multicenter study of diabetes in managed care. Diabetes Care 25:386-389

Ware JE, Gandek B, Rogers BW, Reese PR (1997) MAP-R for Windows: Multitrait/ Multi-Item Analysis Program - Revised User's Guide. Health Assessment Lab, Boston, MA

Welch G, Weinger K, Anderson B, Polonsky WH (2003) Responsiveness of the problem areas in diabetes (PAID) questionnaire. Diabet Med 20:69-72

Williams GC, McGregor HA, Zeldman A, Freedman ZR, Deci EL (2004) Testing a self-determination theory process model for promoting glycemic control through diabetes self-management. Health Psychol 23:58-66

Wroe J (2006) The 3rd International DAWN Summit: from research and practice to large-scale implementation. Practical Diabetes International 23:313-316

doi:10.1186/2193-1801-3-83

Cite this article as: Nicolucci et al:: Benchmarking network for clinical and humanistic outcomes in diabetes (BENCH-D) study: protocol, tools, and population. SpringerPlus 2014 3:83.

\section{Submit your manuscript to a SpringerOpen ${ }^{\circ}$ journal and benefit from:}

- Convenient online submission

- Rigorous peer review

- Immediate publication on acceptance

- Open access: articles freely available online

- High visibility within the field

- Retaining the copyright to your article

Submit your next manuscript at $>$ springeropen.com 